\title{
The demography of giraffe deaths in a drought
}

\author{
G.Mitchell $^{1,2, *}$, S. van Sittert ${ }^{1}$, and J.D Skinner ${ }^{1}$ \\ Centre for Veterinary Wildlife Studies, University of Pretoria, Onderstepoort 0110,South Africa ${ }^{1}$, and Department \\ of Zoology and Physiology, University of Wyoming, 1000 E University Avenue, Laramie, WY 82071, USA². \\ *Author for correspondence (mitchg@uwyo.edu).
}

\section{Summary}

Darwin's theory for the evolution of the long neck of giraffes is that height confers access to browse free of competition from smaller browsers. The theory predicts that survivors of a drought will be the tallest animals in a population. All studies so far have tested this hypothesis by analysis of feeding patterns and behavior. We have studied it by analyzing the demography of deaths in a drought. Using skeletal material from 26 giraffes that died as a result of a drought in south eastern Zimbabwe in 2008, we established the body mass, height, and age of the dead giraffes using allometric equations developed from culled animals. Typical giraffe populations consist of $55 \%$ adults (>6years old), $15 \%$ young adults (3-6 years old), 15\% juveniles (1-3 years old), and 15\% neonates ( $<1$ year old). Skeletons came from $54 \%$ adults, $14 \%$ young adults, and $32 \%$ juveniles. No neonatal skeletons were found. More juveniles died than expected because they have to compete with other browsers for nutrients. Most adult deaths occurred in the tallest and largest males because their daily requirements for browse are highest and could not be met by the amounts available at any level. Thus the survivors of this drought were young adults, a finding contrary to the predictions of Darwin's feeding hypothesis.

\section{Keywords}

Giraffe, drought, feeding hypothesis.

\section{Short title}

Giraffe deaths in a drought

\section{Introduction}

The most widely accepted explanation for the long neck of giraffes (Giraffa camelopardalis) is that their morphology co-evolved with an Acacia sp. savannah woodland (Pellew, 1983a) giving them access to high level browse free from competition with smaller browsers (Cameron \& du Toit, 2007). Although he was reluctant to be drawn into a debate about the feeding advantages of the long neck of giraffes, Darwin entrenched these ideas in a famous passage from his 1888 edition of Origin of Species (Darwin, 1888, p177): "The giraffe, by its lofty stature, much elongated neck, forelegs, head and tongue, has its whole frame beautifully adapted for browsing on the higher branches of trees. It can thus obtain food beyond the reach of other Ungulata or hoofed animals inhabiting the same 
country; and this must be a great advantage to it during dearths. -- So under nature with nascent giraffe, the individuals which were the highest browsers and were able during dearths to reach even an inch or two above the others, will often have been preserved".

Darwin's logic is persuasive and is supported by modern research. Edible biomass is concentrated at high levels where light intensity is greatest: a cubic metre of high level canopy produces three times more browse than is available at levels of less than a metre (Pellew, 1983a), and it is rich in protein and minerals (Sauer et al, 1977). The benefits that flow from eating high level browse include faster growth rates, shorter calving intervals, a younger age of first conception and, therefore, more calves per female and a shorter intergenerational gap, all of which favour survival of the species (Pellew, 1983a).

All attempts so far made to confirm Darwin's hypothesis have studied giraffe feeding patterns and behavior, and the results have been mixed. For example, giraffes often feed at heights that other browsers do (du Toit, 1990), prefer to feed at shoulder height (Young \& Isbell, 1991), most of the time (Leuthold \& Leuthold, 1972; Pellew, 1984), even in the dry season, feeding from the tops of trees only when new shoots are available (Pellew, 1984). There is also a vigilance cost to feeding at high levels (Cameron \& du Toit, 2005), but a long neck is an advantage when lower leaves of trees have been eaten by shorter browsers (Cameron \& du Toit, 2007).

However, a truer test of whether Darwin's hypothesis is correct is not whether a long neck gives access to high level browse, but whether the tallest giraffes survive better than shorter ones in a drought, because it could be predicted from his hypothesis that during a "dearth" the survivors would be the tallest members of any population. Testing this possibility so far has not been done. We have had a rare opportunity to do so, however, and report here an analysis of our findings.

Material and methods

Our study was done in the Bubye Valley Conservancy in south eastern Zimbabwe ( $\left.21^{\circ} 42^{\prime} \mathrm{S}, 29^{\circ} 54^{\prime} \mathrm{E}\right)$ which is approximately $0.75-1$ million acres in extent and has a large resident population of giraffes. The rainfall season is summer, and winters (May to September) are dry and cold: average minimum temperatures $\left(10.1 \pm 3.0^{\circ} \mathrm{C}\right)$ are less than half those in summer $\left(20.7 \pm 1.2^{\circ} \mathrm{C}\right)$. In 2008 the Conservancy experienced a significant drought. In the previous two years $460.5 \mathrm{~mm}$ (2006) and $439.5 \mathrm{~mm}$ (2007) of rain were recorded in the summer months. In 2008 rainfall was $236 \mathrm{~mm}$ and reports from wardens indicated that large numbers of giraffes had succumbed, especially starting in August 2008. The principal source of giraffe browse is Acacia spp. which defoliate in the latter parts of winter (Sauer et al, 1977). When rainfall in late summer (January to May) is good a high water table stimulates Acacia to produce nutritious buds and flowers in August that sustain giraffes until the summer rains arrive. In drought years the lower water table delays both flowering and leaf budding at a time when ambient temperature is still low and demand for food energy is high. In 2006 and $2007248 \mathrm{~mm}$ and $157.5 \mathrm{~mm}$ 
of rain fell in the Conservancy between January and May respectively. In 2008 just $55 \mathrm{~mm}$ fell in the same period precipitating a collapse in browse provision and the subsequent die-off of giraffes.

In April 2009 we drove an $80 \mathrm{~km}$ transect across the Conservancy and collected all 26 giraffe skeletons of animals that had died in the previous 12 months (judged from the characteristics of the carcass) which were visible from the road. This transect covered an estimated $1 \%$ of the total conservancy area. The skeletons were analyzed to establish body mass, height and age. We have established in a separate study on culled giraffes (van Sittert et al, 2010), that there are robust allometric relationships between the length of bones $(\mathrm{mm})$ and body mass $(\mathrm{kg})$ in giraffes, between their height (measured from the sole of the front foot to the occipital crest) and body mass [Mitchell et al, 2009]) and between height and age (Dagg \& Foster, 1976; Pellew, 1983b). The marker bone we used to determine body mass was cervical vertebrae $7(\mathrm{C} 7)$. The predictive equations, which are not gender specific, for these relationships are:

$$
\begin{aligned}
& \text { Body mass }(\mathrm{Mb}, \mathrm{kg})=0.007^{*} \mathrm{C}_{\mathrm{L}} 7^{2.18} \\
& \text { Height }(\mathrm{Ht}, \mathrm{m})=0.47^{\star} \mathrm{Mb}^{0.33} \\
& \text { Age (years })=0.016^{*} \mathrm{Ht}^{4.0}
\end{aligned}
$$

Finally, we compared the demography of the skeletons to the typical population demography of giraffes. We did not analyze the structure of the Bubye Valley population prior to the drought, but analyses reported in other studies (Dagg \& Foster, 1976; Pellew, 1983; Fennessy, 2004; Suraud, 2008) suggest that the standing age distributions of giraffe populations in different places are very similar. We did, however, compare the demography of the skeletons to the structure of the giraffe population of the Conservancy as determined by road strip censuses we made in November 2008 and April 2009, i.e after the drought.

Results

Figure 1 shows the distribution of the giraffe skeletons we collected and Figure 2 shows the demography of typical giraffe populations. These distributions differ significantly $\left(X^{2}=34.4\right.$, $\mathrm{P}<0.0001)$. Figure 1 shows that most skeletons came from animals that fell into two main groups. The first group consisted of young animals typically two years old, weighing $200-300 \mathrm{~kg}$, and having a height of less than 3 metres. This group accounted for $32 \%$ of deaths. The second group comprised animals that were mature, tall and heavy. Typically these animals were greater than 9 years old, weighed $1200 \mathrm{~kg}$ or more and were at least 4.5 metres tall. This group accounted for $54 \%$ of all deaths.

The Figures show three notable differences between the demography of deaths and the demography of a general population. The differences were, first, no skeletal remains of giraffes less than one year 
old were collected. Secondly, young animals (excluding those under one year of age) comprised $32 \%$ of deaths but form ca15\% of a population. Thirdly, as equal numbers of adult males and females are found in a population equal numbers of males and females should have been represented in the skeletal material we collected, but they were not. In mature animals gender can be established from the skull by its mass and horn development (Dagg, 1965; Spinage, 1968). From their skulls we judged that of the 15 mature animals in the sample, thirteen were male, a ratio (87\% male:13\% female) quite different to that in the general population.

Discussion

The primary goal of animals is to obtain sufficient food energy each day to satisfy daily needs (Nagy, 2005). The daily food intake of an herbivorous mammal is described by the equation: $\mathrm{kg}$ food/day = $0.157^{*} \mathrm{Mb}^{0.84}$ and the energy intake by the equation: $\mathrm{kj} / \mathrm{day}=971^{\star} \mathrm{Mb}^{0.73}$ (Calder, 1996). For giraffes, these equations predict that the absolute quantities of browse needed daily are large: a mature $1000 \mathrm{~kg}$ giraffe requires $50 \mathrm{~kg}$ of browse daily that must provide $150000 \mathrm{kj} /$ day of energy, and a $200 \mathrm{~kg}$, one-year-old giraffe requires $14 \mathrm{~kg} /$ day and $50000 \mathrm{kj} /$ day. Therefore, animals that can get access to browse free of competition from other browsers or smaller conspecifics should, theoretically, survive best. Our data show that in a drought deaths were of juveniles and large males. We can speculate that the reason that juveniles 1 to 3 years-old died out of proportion to their numbers in a population was because they had to compete for browse with other browsers such as kudu (Tragelaphus strepsiceros) and eland (Tragelaphus oryx), which can browse up to a height of two metres (du Toit, 1990). Adults of these species also die preferentially during droughts (Knight, 1995). Fewer adult females died than males because their metabolic demands were less: the estimated body masses of the two adult (>6) females in the sample were 850 and $780 \mathrm{~kg}$ compared with the average body mass estimate for adult males that died of $1287.2 \pm 104.8 \mathrm{~kg}$ i.e. approximately $40 \%$ higher. Consequences of drought for females are that foetuses die and are resorbed or aborted, or lactation ceases and unweaned calves then have no source of nutrients and die. Their remains are highly desired, easily dismembered, and quickly devoured or dispersed by scavengers. Scavengers present on the Conservancy include all three large felids (Panthera. leo, Panthera pardus, Acinonyx jubatus), both hyaena sp (Crocuta crocuta, Parahyaena brunnea) and canids (Lycaon pictus, Canis mesomelas, Canis adustus). The resorbtion of foetuses and presence of these scavengers can account for the absence of neonatal skeletons in our sample. Support for this conclusion came from the population censuses we made in November 2008 and April 2009. This census, of 314 giraffes across a 392km transect, showed that survivors could be classified as $85.7 \%$ "adult" ( $75 \%$ of them female), $12.4 \%$ "young adult" and just $1.9 \%$ yearlings. This census is somewhat biased by the annual preferential culling of 150 adult male giraffes (ca8\% of adult males in the Conservancy population) to provide meat. On the other hand, this cull reduces the population pressure on browse by tall males and it is likely, therefore, that even more large animals might have died in the drought than we found, if there had not been any culling. The reason that the biggest animals died was, we believe, simply because their daily requirement for browse is highest and the amount of browse available to them during the 
drought almost certainly was well below the amount needed to maintain their metabolism. Abnormally cold weather might have contributed as giraffes are susceptible to cold (Clauss et al, 1999) but winter and early summer ambient temperatures in 2008 did not differ significantly from those of the two previous years.

In general, while it is possible that another cause was responsible for the selective die-off of giraffes we have found, we are confident that the drought played a significant and dominant role. If so, then the animals that survived this drought were not, as predicted by Darwin's hypothesis, the tallest and most able to reach "even and inch or two above the others". The survivors were young adults or adult females. Therefore, Darwin's hypothesis about the survival advantages of a long neck is not supported by our analysis. A greater determinant of survival appears to be the ratio of metabolic demand: available browse. In the case of juveniles they must compete for the browse they need. In the case of tall, large males their requirements were not matched by availability. The survivors of droughts are giraffes in their reproductive years and hence those most likely to breed successfully when conditions become favourable.

Acknowledgements

We thank the management and staff of the Bubye Valley Conservancy, Zimbabwe, for their support and sponsorship of this study. Funds were provided by the Don Craib Trust (JDS), the University of Wyoming (GM), and the University of Pretoria (SvS). Technical support was provided by Blake Wilelmi, David Roberts, Kyle Piearse, and Declan Gallagher.

References

Calder, W.A. 1996. Size, Function, and Life History. New York: Dover Publications.pp431.

Cameron, E.Z. \& du Toit, J.T. 2005. Social influences on vigilance behaviour in giraffes, Giraffa camelopardalis. Anim. Behav. 69: 1337-1344.

Cameron, E.Z. \& du Toit, J.T. 2007. Winning by a neck: Tall giraffes avoid competing with shorter browsers. Am. Nat. 169(1): 130-135.

Clauss M., Suedmeyer K., Flach E.J. 1999. Susceptibility to cold in captive giraffe (Giraffa camelopardalis).Proceedings of the American Association of Zoo Veterinarians. p183-186.

Dagg, A.I. 1965. Sexual differences in giraffe skulls. Mammalia 29: 610- 612.

Dagg, A.I. \& Foster, J.B. 1976. The giraffe: Its biology, behaviour, and ecology. New York: Van 
Nostrand Reinhold.pp210.

Darwin, C.R. 1888. The origin of species: By means of natural selection, the preservation of favoured races in the struggle for life. $6^{\text {th }}$ Edition. London: John Murray. pp 177.

du Toit, J.T. 1990. Feeding-height stratification among African browsing ruminants. Afr. J. Ecol. 28: $55-61$.

Fennessy, J.T. 2004. Ecology of desert-dwelling giraffe Giraffa camelopardalis angolensis in northwestern Namibia. PhD Thesis, University of Sydney, Australia.

Knight, H.H. (1995). Drought-related mortality of wildlife in the southern Kalahari and the role of man. African Journal of Ecology. 33: 377-394.

Leuthold, B.M. \& Leuthold, W. 1972. Food habits of giraffe in Tsavo National Park, Kenya. E. Afr. Wildl. J. 10: 129- 141.

Mitchell, G., van Sittert, S. \& Skinner, J.D. 2009. Sexual selection is not the origin of long necks in giraffes. J. Zool. (Lond.) 278: 281-286.

Nagy, K.A. 2005. Field metabolic rate and body size. J. Exp. Biol. 208: 1621-1625.

Pellew, R.A. 1983a. The giraffe and its food resource in the Serengeti. I.

Composition, biomass, and production of available browse. Afr. J.Ecol. 21:241-267.

Pellew, R.A. 1983b. The giraffe and its food resource in the Serengeti. II. Response of the giraffe population to changes in the food supply. Afr. J. Ecol. 21: 269-283.

Pellew, R.A. 1984. The feeding ecology of a selective browser, the giraffe (Giraffa camelopardalis tippelskirchi). J. Zool.(Lond.) 202:57-81.

Sauer, J.J.C., Theron G.K. \& Skinner J.D. 1977. Food preferences of giraffe Giraffa camelopardalis in the arid bushveld of the western Transvaal. S. Afr.J. Wildl. Res. 7(2): 53-59.

Suraud, J-P. 2008. Giraffe of Niger, 2007 census and perspectives. Giraffa 2: 4-6.

Spinage, C.A. 1968. Horns and other bony structures of the skull of the giraffe, and their functional significance. E. Afr. Wildl. J. 6: 53-61.

Van Sittert, S.J., Skinner, J.D. \& Mitchell, G. 2010. From fetus to adult - an allometric analysis of the 
giraffe vertebral column. J. Exp. Zool.(Mol.Dev.Evol.). 314B (in press)

Young, T.P. \& Isbell, L.A. 1991. Sex differences in giraffe feeding ecology: energetic and social constraints. Ethology 87: 79-89.

Figure Legends

Fig 1. Frequency distribution of deaths by age, height and body mass. Age categories are $1=1-3 \mathrm{yrs}$, $2=3-6,3=>6$. Height categories are $1=<3 \mathrm{~m}, 2=3-4,3=>4$. Body mass categories are $1=200-$ $400 \mathrm{~kg}, 2=400-800,3=>800$.

Fig 2. Frequency distribution of giraffe populations in Nairobi National Park (Dagg \& Foster, 1976) and Serengeti (Pellew, 1983b). The adults $>6$ years of age consisted of $25 \%$ males and $31 \%$ females. 


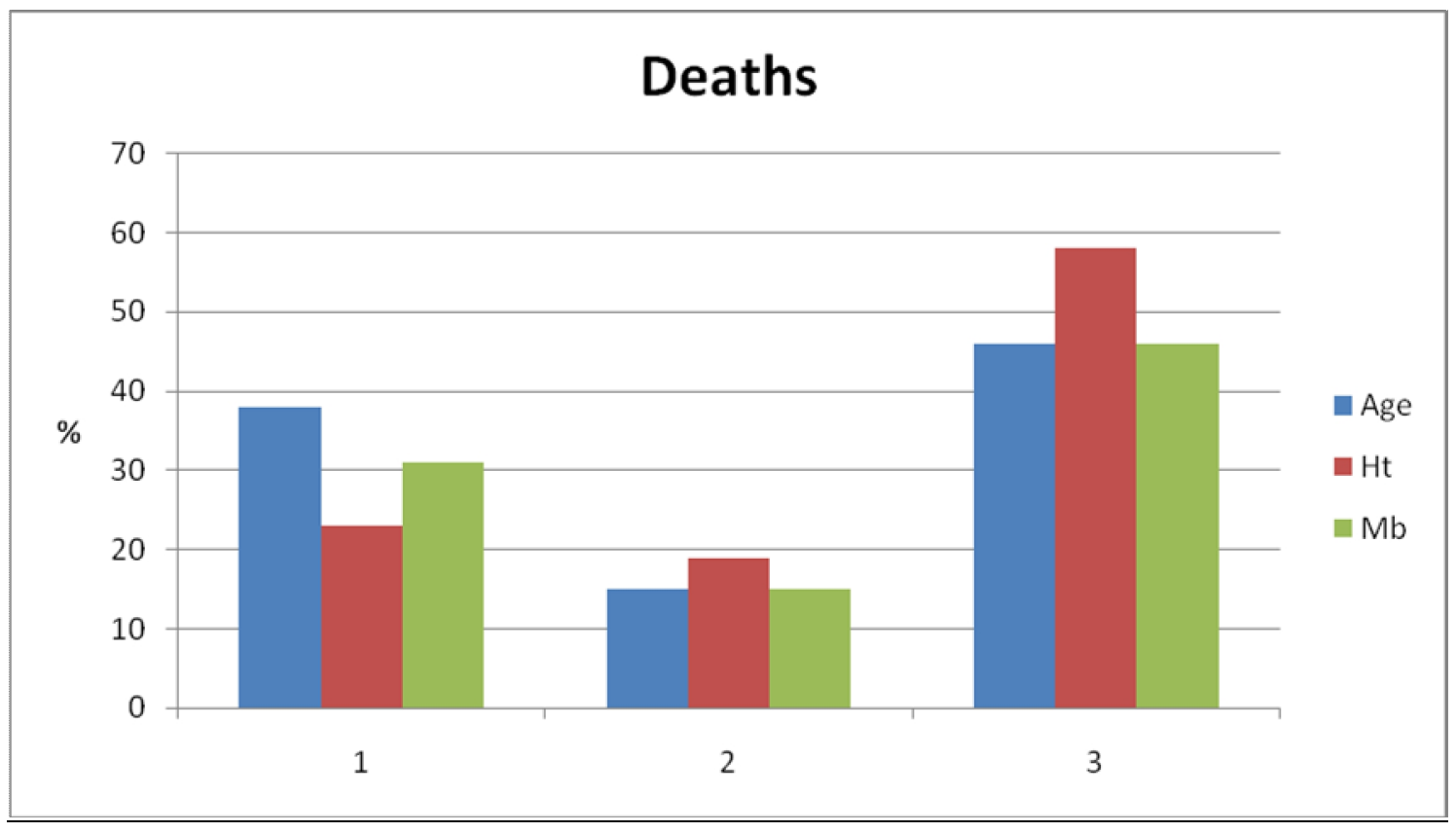

Fig 1

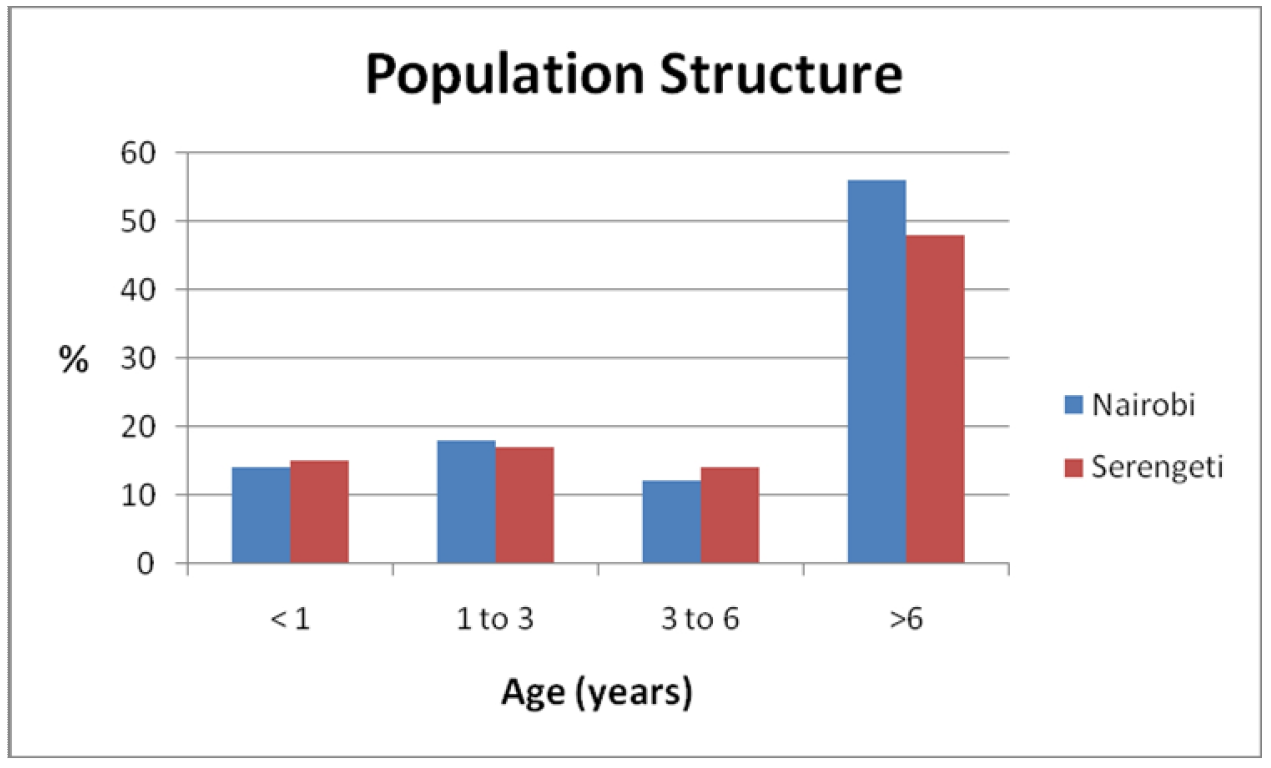

Fig 2 